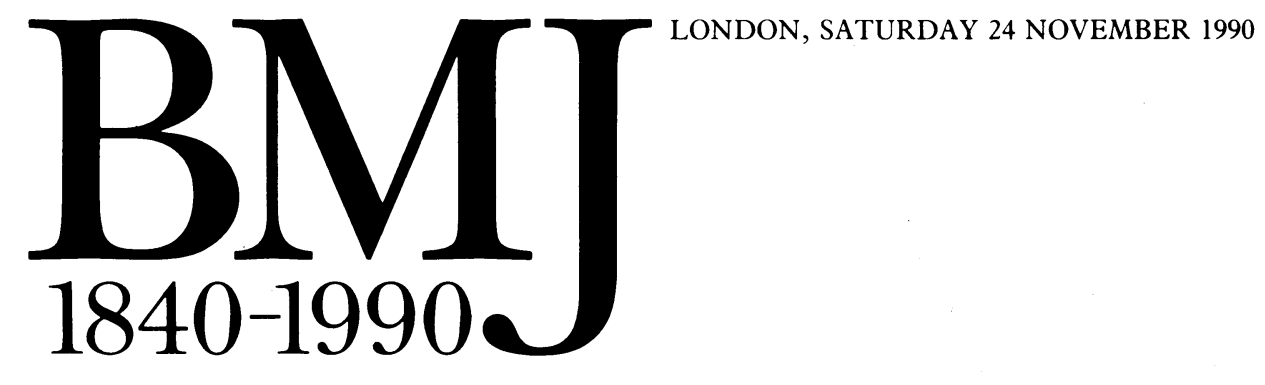

\title{
Unexplained haematuria
}

\author{
May be due to slowly progressive glomerular disease
}

Asymptomatic microscopic haematuria is common. The often quoted prevalence of $2 \cdot 5 \%$ in community based studies is based on middle aged men undergoing private health assessment, ${ }^{1}$ and detection rates may be much higher in older people - up to $22 \%$ in the over $60 \mathrm{s.}^{2}$ Increasing numbers of cases are being detected in screening programmes using dipstick urine testing, but many of these abnormal dipstick test results are regarded as inconsequential by both hospital doctors $^{3}$ and general practitioners. ${ }^{1}$ Are they right to regard them so and what then is the point of screening for haematuria in asymptomatic people?

Doctors tend to disregard the results of reagent strip tests when microscopy fails to confirm haematuria, ${ }^{+}$yet dipstick testing may be more accurate than the urine microscopy performed in many hospital laboratories. The Addis count, based on assessing erythrocyte excretion over 12 hours, ${ }^{5}$ has been superseded by measuring excretion rates in urine collected over a limited time or cell counts per unit volume in fresh, spot urine specimens using a counting chamber ${ }^{67}$; phase contrast illumination and supravital stains may be used to enhance the accuracy of microscopy. ${ }^{7}$ Most routine laboratory services are, however, reporting results as cells per high power field using a slide and coverslip preparation with simple bright field microscopy; these methods often fail to detect important urinary abnormalities, correlating poorly with counting chamber results. ${ }^{6}$ Reagent strip analysis for haematuria is practicable and reliable, with sensitivities of 91$100 \%{ }^{8}$ and specificities greater than $98 \%$ when phase contrast microscopy is used as the reference standard..$^{79}$ Moreover, dipstick haematuria correlates closely with underlying disease, even in the presence of normal findings on microscopy. ${ }^{21011}$

The prevalence of underlying disease and our ability to influence its cause determine the potential value of any screening programme. The arguments in favour of screening for haematuria are strong in the elderly (in whom urological malignancies are particularly common ${ }^{21}$ ) but less clear in younger adults. Woolhandler et al concluded from population studies in young adults that a prevalence of serious treatable disease of less than $2 \%$ in subjects with isolated haematuria was too low to justify unselective urinary screening, ${ }^{8}$ but we do not know the long term outcome in the many people with apparently less serious, but largely undefined disease. This is particularly relevant given the underrepresentation of glomerular disease in the published reports on the subject. These are largely weighted towards urological conditions and hence biased towards short term outcome measures more appropriate to assessing neoplastic urothelial disease.
What is of concern in younger adults (in whom urological malignancy is uncommon ${ }^{4}$ ) is the slowly progressive decline in renal function that may occur in glomerular diseases presenting with asymptomatic haematuria, even in the absence of significant proteinuria or hypertension. ${ }^{12}$ The only study in which a population screened for microscopic haematuria was systematically subjected to renal biopsy, conducted in young Asian military recruits aged 17-25, identified glomerular disease in $54 \%$ of index patients. ${ }^{13}$ Berger's disease, or IgA nephropathy, is probably the single commonest underlying histopathological diagnosis, ${ }^{10}{ }^{1+16}$ and end stage renal failure is estimated to occur in $16-34 \%$ of patients with this condition within 20 years of initial presentation. ${ }^{17}$ Furthermore, now that thin membrane nephropathy has been described as an important cause of asymptomatic haematuria in adults ${ }^{18}$ even higher rates of glomerular disease may be found by more precise morphometric assessment of renal histology. ${ }^{19}$

Whether early diagnosis will improve outcome in these patients is unknown, although control of hypertension and dietary manipulation may well prolong renal survival in those with progressive glomerular disease. ${ }^{20} \mathrm{~A}$ definitive diagnosis would also prevent unnecessary repeated urological investigations in patients with persistent unexplained urinary blood loss. ${ }^{14}$

The medical complications and costs of investigation may, however, outweigh the benefits of early diagnosis. The invasive urological assessment that is used in patients with other clinical or laboratory markers of nephrourological disease has been recommended for investigating adults with asymptomatic and isolated urinary blood loss. ${ }^{4}$ For those whose haematuria remains unexplained after cystourethroscopy and urography renal histology will provide a definitive diagnosis in $70-100 \%$ of cases..$^{101+15}{ }^{19}$ Clearly, these procedures have risks ${ }^{8}$ and many British nephrologists consider that establishing a diagnosis by renal biopsy in this group of patients may not be justified..$^{21}$

An alternative low risk, cost effective evaluation is now possible with newer techniques of urine analysis. A recent study used variations in urinary erythrocyte morphology to differentiate glomerular from non-glomerular sources of urinary blood loss in 319 patients aged $10-90$ with unexplained haematuria detected on dipstick screening. ${ }^{22}$ Non-glomerular urinary red cell morphology was identified in $123(39 \%)$ patients by interference microscopy. Standard urological assessment established a urothelial diagnosis in 104 (including 16 malignancies). The remaining 193 patients, who had dysmorphic glomerular erythrocyturia, were spared invasive 
urological investigation and monitored uneventfully after a non-invasive nephrological assessment. After a mean follow up of 3.5 years only two had developed non-glomerular haematuria after repeated urine microscopy, both of whom were later found to have underlying urothelial disease.

Despite its initial promise this technique has not been widely adopted in the United Kingdom, ${ }^{21}$ probably because of concern about interobserver variations in reporting microscopy results. ${ }^{23}$ Interest has instead been directed towards using automated haematological analysers to assess urinary erythrocyte morphology, ${ }^{2+25}$ but the inaccuracy of this technique at low red cell counts may limit its practical application. ${ }^{26}$ In our experience variations in reporting microscopy findings may be reduced with a more precise classification of urinary red cell variants (unpublished observations) and the accuracy of automated analysers substantially enhanced by using simple modifications. ${ }^{27}$

Over the next few years these newer techniques may well achieve acceptable standards of accuracy and reproducibility for routine use and, with the adoption of widespread urinary screening by general practitioners, are likely to have an impact on the practice of both nephrologists and urologists. Until then further investigation of patients with asymptomatic dipstick haematuria, even in the absence of confirmatory microscopy or other markers of underlying disease, is recommended. We also suggest a standard non-invasive nephrological assessment and long term follow up to detect potentially progressive renal disease in those patients with urologically unexplained blood loss.

MARK P DE CAESTECKER Research Fellow

FRANCIS W BALLARDIE

Manchester Royal Infirmary, Honorary Consultant Nephrologist
1 Ritchie CR, Bevan EA, Collier StJ. Importance of occult haematuria found at screening. BMf 1986;292:681-3.

2 Britton JP, Dowell AC, Whelan P. Dipstick haematuria and bladder cancer in men over 60: results of a community study. BMf 1989;299: 1010-2.

3 Morgan AG. Is routine testing in outpatient clinics useful? BM 1988;297:1173.

4 Bullock N. Asymptomatic microscopical haematuria. BMF 1986;292:647.

5 Addis T. The number of formed elements in the urinary sediment of normal individuals. $f$ Clin Invest 1926;2:409.

Kesson AM, Talbot JM, Gyory AZ. Microscopic examination of urine Lancet 1978;ii:809-12.

7 Fairley KF. Urinalysis. In: Schrier RW, Gottschalk CW, eds. Diseases of the kidney. th ed. Frankfurt: Strauss and Welt, 1988

8 Woolhandler S, Pels RJ, Bor DH, Himmelstein DU, Lawrence RS. Dipstick urinalysis screening for asymptomatic adults for urinary tract disorders. FAMA 1989;262:1215-9.

9 Arm JP, Peile EB, Rainford DJ, Strike PW, Tettmar RE. Significance of dipstick haematuria. 1 Correlation with microscopy of the urine. Br $\mathcal{J}$ Urol 1986;58:211-7.

10 Arm JP, Peille EB, Rainford DJ. Significance of dipstick haematuria. 2. Correlation with pathology. Brf Urol 1986;58:218-23.

11 Messing EM, Young TB, Hunt VB, Emoto SE, Wehbie JM. The significance of asymptomatic microhematuria in men 50 or more years old: findings of a home screening study using urinary dipsticks. F Urol 1987;137:919-22.

12 Feehally J, Walls J. Asymptomatic microscopical haematuria. BMf 1986;292:1273.

13 Chen BTM, Ooi BS, Tan KK, Lim CH. Comparative studies of asymptomatic proteinuria and hematuria. Arch Intern Med 1974;134:901-5.

14 Michael J, Jones NF, Davies DR, Tighe JR. Recurrent haematuria: role of renal biopsy and Co

15 Copley JB, James MAJ, Hasbargen JA. Idiopathic hematuria: a prospective evaluation. Arch Intern Med 1987;147:434-7.

16 Ballardic FW, O'Donoghue DJ, Feehally J. Increasing frequency of adult IgA nephropathy in the UK? Lancet 1987;ii:1205.

17 D'Amico G. The commonest glomerulonephritis in the world: IgA nephropathy. $Q$ f Med 1987;245:709-27.

18 Dische FE, Weston MJ, Parsons V. Abnormally thin glomerular basement membranes associated with hematuria, proteinuria or renal failure in adults. Am $\mathcal{F}$ Nephrol 1985;5:103-9.

19 Tiesbosch ATMG, Frederik PM, van Breda Vriesman PJC, et al. Thin basement membrane nephropathy in adults with persistent hematuria. $N$ Engl $\mathcal{F}$ Med 1989;320:14-8.

20 Fine LG. Preventing the progression of human renal disease: have rational therapeutic principles emerged? Kidney Int 1988;33:116-28.

21 Feehally J, O'Donoghue DJ, Ballardie FW. Current nephrological practice in the investigation of haematuria: relationship to incidence of IgA nephropathy. $\mathcal{f} R$ Coll Physicians Lond 1989.23. 228-31.

22 Schramek P, Schuster FX, Georgopoulos M, Porpaczy P, Maier M. Value of urinary erythrocyte morphology in assessment of symptomless microhaematuria. Lancet 1989;ii:1316-9.

23 Venkat-Raman G, Pead L, Lee HA, Maskell R. A blind controlled trial of phase contrast microscopy by two observers for evaluating the source of haematuria. Clin Nephrol 1986;44: $304-8$

24 Schichiri M, Oowada A, Nishio Y, Tomita K, Shiigai T. Use of autoanalyser to examine urinary red cell morphology in the diagnosis of glomerular haematuria. Lancet 1986;ii:781-2.

25 de Caestecker MP, Hall CL, Basterfield PT, Smith GJ. Localisation of haematuria by red cell analysers and phase contrast microscopy. Nephron 1989;52:170-3.

26 Gibbs DD, Lynn KL. Red cell volume distribution curves in the diagnosis of glomerular and nonglomerular haematuria. Clin Nephrol 1990;33:143-7.

27 de Caestecker MP, Gower PG, Ballardie FW. Improved urinary erythrocyte morphometry using red cell analysers. Kidney Int (in press).

\section{First line treatment in hypertension}

\section{Still $\beta$ blockers and diuretics}

The vigorous debate in the $B M \mathcal{F}$ on first line treatment for hypertension $^{12}$ indicates the fragile nature of the agreed recommendations of the British Hypertension Society. ${ }^{3}$ I had suspected at the time that the recommendations of the working party, which I had the dubious privilege of chairing, had all the durability of a peace settlement in Beirut, and so it has proved as members of our working party pull out their artillery. Nevertheless, I believe that the conclusions that we reached still stand and are, indeed, if anything reinforced by more recent evidence.

We concluded that diuretics and $\beta$ blockers were still the preferred first line treatment in patients with uncomplicated hypertension. The reasons are straightforward. These drugs have been shown beyond dispute to reduce the risk of stroke in hypertensive patients. At the time our report was written a pooled analysis of the large trials of treatment had suggested, however, a disappointingly non-significant impact of treatment on coronary artery disease. ${ }^{4} \mathrm{~A}$ more recent analysis with a slightly different mix of trials (and authors) concluded that the incidence of myocardial infarction was reduced by antihypertensive treatment, although the confidence intervals of this analysis were so wide that the results were also compatible with virtually no effect and complete reversal of hypertensive risk. ${ }^{5}$
We have no evidence from trials of the effect of the newer classes of drugs - that is, the angiotensin converting enzyme inhibitors, calcium antagonists, and $\alpha$ blockers - on either strokes or heart attacks. There is a further consideration that is of growing importance to us all. A year's course of bendrofluazide costs $£ 2-£ 4$; for calcium antagonists or angiotensin converting enzyme inhibitors the figure is $£ 100-£ 200$. Between $20 \%$ and $30 \%$ of the adult population are candidates for lifelong antihypertensive treatment, and the new contractual arrangements will inevitably encourage doctors to identify more of these patients. The newer drugs may or may not be better at reducing the risk from myocardial infarction. There are no data to guide us. The indications are hardly propitious. Trials of calcium antagonists after myocardial infarction, justified by theoretical arguments, far from showing efficacy, showed a slight worsening of prognosis. ${ }^{6}$

In the absence of clinical evidence the pharmaceutical industry has promoted a series of scientific hypotheses which predict that the newer drugs might be better at preventing myocardial infarction. Thus we have been told that the calcium antagonists reverse a specific abnormality of smooth muscle calcium handling and that angiotensin converting enzyme inhibitors correct angiotensin II receptor modulation, cardiovascular structural remodelling, and (most recently) 